\title{
Cellulose Nanofibers as Functional Biomaterial from Pineapple Stubbles via TEMPO Oxidation and Mechanical Process
}

\author{
Kenly Araya-Chavarría ${ }^{1} \cdot$ Ruth Rojas $^{1} \cdot$ Karla Ramírez-Amador $^{1} \cdot$ Belkis Sulbarán-Rangel $^{2}$ (D) Orlando Rojas $^{3,4}$. \\ Marianelly Esquivel-Alfaro ${ }^{1}$
}

Received: 25 May 2021 / Accepted: 18 October 2021 / Published online: 23 October 2021

(c) The Author(s) 2021

\begin{abstract}
The pineapple fruit when harvested generates a large amount of residual biomass; this biomass can be used to generate value-added products such as cellulose nanofibers. This study was focused on the isolation of CNF from pineapple leaves after oxidation pretreatment with 2,2,6,6-tetramethylpireridine-1-oxyl, followed by mechanical deconstruction of the fibers via combination of grinding and microfluidization process. One and two microfluidization passes were applied to bleached and unbleached fibers, respectively. The implications of these findings are that during the production process it is possible to reduce the amount of chemicals needed for bleaching and the energy involved in the mechanical microfluidization process. Such process yielded corresponding fibril lengths and widths in the range of 481-746 nm and 16-48 nm. The respective electrostatic charges, as measured by zeta potentials, were $-41 \mathrm{mV}$ and $-31 \mathrm{mV}$. As expected, the CNF crystallinity was higher than that of the starting material, especially for the cellulose. However, the thermal stability was reduced, showing two degradative processes due to the chemical modification of the fibers. The CNF produced from pineapple leaves has a potential to be used like biomaterial in diverse applications while representing a viable alternative to producers, which face serious environmental and health challenges given the large volume of biomass that is otherwise left in the fields as waste.
\end{abstract}

Belkis Sulbarán-Rangel

Belkis.sulbaran@academicos.udg.mx

$\triangle$ Marianelly Esquivel-Alfaro

mesquive@una.ac.cr

1 Polymers Research Laboratory (POLIUNA), Chemistry Department, Universidad Nacional, Heredia, Costa Rica, USA

2 Department of Water and Energy, University of Guadalajara, Campus, Tonalá, México

3 Department of Bioproducts and Biosystems, School of Chemical Engineering, Aalto University, Espoo, Finland

4 Departments of Chemical \& Biological Engineering, Chemistry and, Wood Science, University of British Columbia, Vancouver, BC, Canada 


\section{Graphic Abstract}

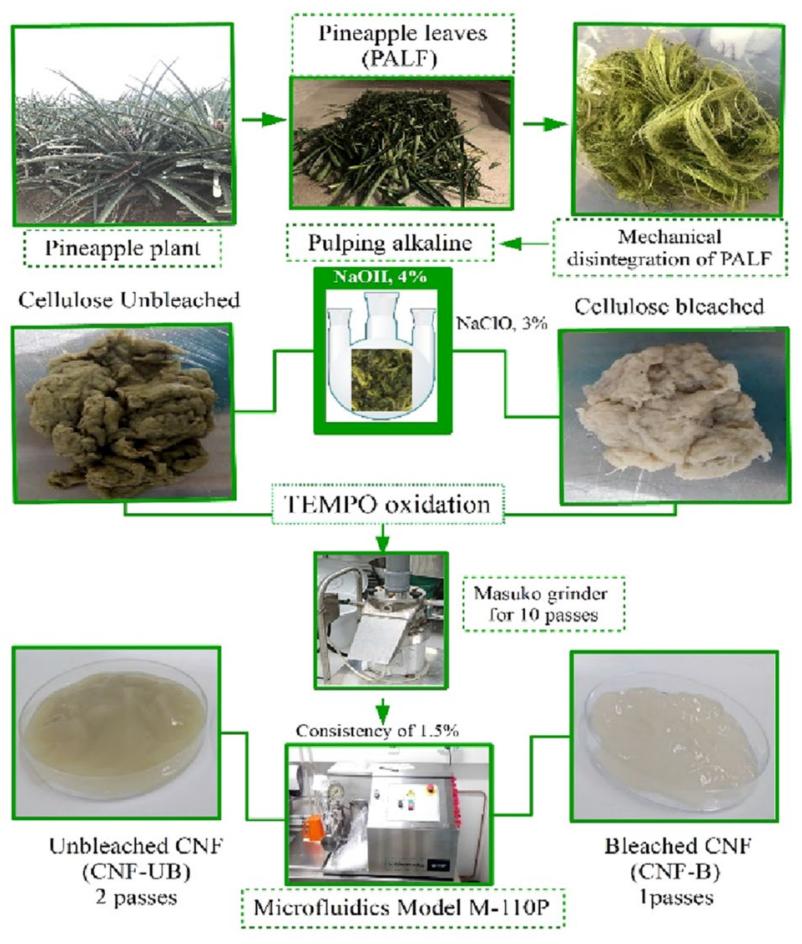

Keywords Natural resources $\cdot$ Waste management and disposal $\cdot$ Sustainability $\cdot$ Biomaterial

\section{Statement of Novelty}

The novelty of this investigation was to produce bleached and unbleached cellulose nanofibers from pineapple leaves using an oxidative pretreatment with 2,2,6,6-tetramethylpiperidine1-oxy (TEMPO) followed by mechanical combination of grinding and microfluidization process. Moreover, the novelty was to take advantage of pineapple stubble waste and give it a beneficial use for the elaboration of advanced materials. Through this process, it was found that the PALF is a suitable source for the extraction of nanofibers and the TEMPO pretreatment reduced the number of steps in the microfluidization process. On the other hands, the characteristics of nanofibers was similar independent of the cellulose (bleached and unbleached). The implications of these findings are that during the production process it is possible to reduce the amount of chemicals needed for bleaching and reduce the energy involved in the mechanical microfluidization process. This will reduce the environmental impact and the cost of production of the CNF.

\section{Introduction}

Costa Rica is a world leader in fresh pineapple exports. In 2020, for example, over 2 million tons of pineapples were exported, primarily to the United States and the European Union, equivalent to 943 million US dollars [1,2]. Upon harvesting the pineapple fruit, all the residual biomass is left in the field, generating a large quantity of stover. Stover is mainly composed of the leaves and stalk of the plants. This lignocellulosic material is difficult to degrade and possesses a large quantity of water, which attracts plagues such as stable flies. It is estimated that for every acre of cultivated pineapple, 200 tons of residue is generated. The yearly average of pineapple stover represents approximately 3 million tons [3, 4]. Given that this biomass is difficult to degrade in the field, the method most used for disposal is to cut the stover and then apply herbicides and other agents until dried, followed by an eventual incineration. The use of agrochemicals generates an adverse impact on the environment and contaminates aquifers, soil and air. Therefore, it is important to find a way to use this material for a secondary use [5].

The main components in the biomass from pineapple crops include cellulose, hemicelluloses, lignin as well as pectins, waxes, and water-soluble substances [6-9]. They are 
present in pineapple leaves fibers (PALF), which are characterized by elongated structures consisting of a system of vascular bundles that are present in the form of fibrous cells. These fibers can be obtained by mechanical elimination of the epidermal tissue and, in spite of their abundance, are typically very hygroscopic and inexpensive but exhibit superior mechanical properties [10]. PALF are associated with high cellulose content (70\% to $80 \%$ ) and a relatively low microfibrillar angle 14 [11]. It has been reported in other investigations that cellulose can be transformed on a nanometric scale to obtain nanocellulose, as cellulose nanofibers (CNF) or cellulose nanocrystals (CNC) [12]. The sources that have been reported for obtaining nanocellulose are very varied; they can be hardwoods [13, 14], softwoods [15], non-timber plants [16], agro-industrial waste [17, 18], among others. The methods for obtaining nanocellulose are also varied, the most common to obtain $\mathrm{CNC}$ are the chemical processes of acid hydrolysis, and to obtain CNF is the mechanical process of microfluidization [12]. The most important aspect is to determine the extraction method, according to the initial raw material, to have the best performance and best characteristics of the nanocellulose obtained. The nanocellulose can be used to improve the properties of diverse materials and modify the rheology of cement slurries, gels, paints, and cosmetics, as well as food additives and pharmaceutical excipients [18-21].

The biomass generated in pineapple production has been used mainly to extract cellulose nanocrystals. The CNC obtained are by acid hydrolysis and it has been reported that they are extracted from different parts of the pineapple plant such as the crown [22, 23], the stem [3], the peel [24] and the leaves $[25,26]$. Due to the cellulosic availability in pineapple plant, it is important to explore the possibility of producing $\mathrm{CNF}$ from this raw material. The main difference between $\mathrm{CNC}$ previously reported by other authors and CNF is the morphology. Nanofibers have diameters in the order of nanometers and lengths in the order of micrometer. This difference will influence the final application given the new material. For example, $\mathrm{CNC}$ are shorter and smaller and have better resistance properties and greater crystallinity than cellulose nanofibers and can be used as reinforcement materials [24]. Cellulose nanofibers can crosslink and form high strength nanostructures for other applications [27]. Accordingly, the novelty of this research is producing CNF from pineapple leaves white cellulose bleached and unbleached using an oxidative pretreatment with TEMPO followed by mechanical combination of grinding and microfluidization process. The pretreatment of the fibers by TEMPO oxidation enhances the dispersibility in water, given the electrostatic repulsion generated by the formation of anionic carboxylate groups [28]. This will help to reduce the steps through the microfluidizer and, therefore, the energy consumption of the mechanical processes will be reduced. The high electrical energy consumption typical of mechanical nanocellulose production is a significant drawback, from the point of view of both environmental impact and production cost [15].

\section{Materials and Methods}

\section{Obtainment of the Material and Chemical Reagents}

The pineapple residues, namely, pineapple leaves (PALF), were collected from a pineapple estate from the company Piñales de Santa Clara, located in Sarapiquí, Heredia, Costa Rica. The chemical reagents used included sodium hydroxide $(\mathrm{NaOH})$, sodium hypochlorite $(\mathrm{NaClO})$ for the bleaching process, and sodium bromide $(\mathrm{NaBr})$, hydrochloric acid $(\mathrm{HCl})$ and 2,2,6,6-tetramethylpiperidine-1-oxyl (TEMPO) for oxidation. All the reagents were acquired from Sigma-Aldrich.

\section{Chemical Composition of the Pineapple Leaves}

The chemical composition of the pineapple leaves were determined following the ASTM methods. The cellulose content was determined using the ASTM D1721 [29], acidsoluble lignin content was determined using ASTM D110621 [30]. The extractable compounds in acetone were determined according to ASTM D1104-78 [31] while the ash content with ASTM D3174-12 [32].

\section{Cellulose Extraction from Pineapple Leaves}

The pineapple leaves were mechanically disintegrated in a debarker to separate the fibers, then they were cut into 0.5$\mathrm{cm}$ pieces and stored at $4{ }^{\circ} \mathrm{C}$ until use; the material was never dried. The debarked material underwent an alkaline treatment with a dissolution of $\mathrm{NaOH}$ at $4 \% \mathrm{~m} / \mathrm{m}$ at $80^{\circ} \mathrm{C}$ for $2 \mathrm{~h}$ (unbleached sample). An alternative bleaching treatment was applied to the previously prepared samples using $\mathrm{NaClO}$ at $3 \% \mathrm{~m} / \mathrm{m}$ at room temperature for $4 \mathrm{~h}$.

\section{TEMPO Treatment of Pineapple Cellulose}

The cellulose, with and without bleaching, were processed with a Masuko grinder (KM, FRYMA-Maschinenbau, Finland) for 10 passes. Then, $15 \mathrm{~g}$ of each bleached and unbleached samples were used for TEMPO oxidation at $1 \%$ solids content, using $0.1 \mathrm{mmol}$ TEMPO per g of cellulose and $1 \mathrm{mmol}$ of $\mathrm{NaBr}$ per $\mathrm{g}$ of cellulose. The oxidation through TEMPO began when sodium hypochlorite at $10 \%$ $\mathrm{m} / \mathrm{v}$ was added, corresponding to $1.2 \mathrm{mmol}$ for each $\mathrm{g}$ of cellulose, under constant stirring and adjusting the $\mathrm{pH}$ between 10 and 11 . After $3 \mathrm{~h}$ of the reaction, the TEMPO-oxidized 
fibers were washed three times with distilled water before filtration.

\section{Extraction of Cellulose Nanofibers}

The CNF were extracted by mechanical treatment with a microfluidizer (Microfluidics, Model M-110P) using the $400 \mu \mathrm{m}$ and $200 \mu \mathrm{m}$ chambers arranged in series. Subsequently, the material was passed once in the case of bleached cellulose and twice for unbleached fibers. In both cases the $200-\mu \mathrm{m}$ and $100-\mu \mathrm{m}$ chambers were used, yielding the CNF. The equipment used an intensifying pump that increased the pressure in the chamber, which favored the interaction between the fibers and the shearing forces and impact against the fibrillation currents. The samples obtained from the microfluidizer included bleached CNF (CNF-B) and unbleached CNF (CNF-UB).

\section{Cellulose Nanofibers Characterization}

The degree of oxidation was determined on the bleached and unbleached pineapple cellulose samples that were pretreated with TEMPO samples. The samples were placed in water with $0.001 \mathrm{M} \mathrm{NaCl}$ with constant stirring, then $0.5 \mathrm{M}$ HCL was added until a pH between 2.5 and 3.0 was reached. $0.05 \mathrm{M} \mathrm{NaOH}$ was added until the constant part of the curve was reached and a $\mathrm{pH}$ of 11 was reached. The carboxylate content of the sample was determined from the conductivity curve using a conductimeter (Thermo Scientific Orion 3 star, USA). Electrical conductivity titration was used to determine the aldehyde content of the bleached and unbleached samples by oxidization with an aqueous solution of $\mathrm{NaClO} 2$ at $\mathrm{pH} 4$ and 5 for the selective conversion from aldehyde to carboxylate groups [28]. The degree of oxidation was determined according to Eq. 1:

$D O=\frac{162 C\left(V_{2}-V_{1}\right)}{m-36 C\left(V_{2}-V_{1}\right)} 100$

where $\mathrm{C}$ is the $\mathrm{NaOH}$ concentration, $\mathrm{V}_{1}$ and $\mathrm{V}_{2}$ are the volumes of $\mathrm{NaOH}$, and $m$ is the weight of the oven-dried sample. The degree of oxidation refers to the quantity, in percentage, of hydroxymethyl groups that are present in the cellulose that are oxidized into carboxyl groups during TEMPO oxidation.

Atomic force microscopy (AFM) was performed using a MultiModeTM Scanning Probe Microscope (Digital Instruments, Inc., USA). The bleached and unbleached CNF samples were prepared by spin coating using only the supernatant of $0.01 \% \mathrm{w} / \mathrm{w}$ nanofibers on a mica substrate and dried at room temperature. The images were acquired in tapping mode and analyzed using Image J 1.45 software. FTIR-ATR spectroscopy was used to detect any chemical changes in the nanofibers that may have occurred during treatment. Attenuated total reflectance (ATR) was used to obtain a spectrum of each sample in the range of $4000 \mathrm{~cm}^{-1}$ to $400 \mathrm{~cm}^{-1}$. The spectral output was registered in transmittance mode as a function of the wavelength in an FTIR (Thermo Scientific, IS50 equipment, USA). Thermogravimetric analysis (TGA) was performed to compare the thermal stability of the TEMPO-oxidized bleached and unbleached CNF using a TA Instruments Q500, USA TGA equipment,, under an inert atmosphere and in the temperature range between $50{ }^{\circ} \mathrm{C}$ and $600{ }^{\circ} \mathrm{C}$. The zeta potential of the nanofibers was determined using a Zetasizer Nano-ZS90, UK, which used $1 \mathrm{~mL}$ of the cellulose nanofiber suspension at $0.35 \%$ solids. X-ray diffraction analysis was carried out with $\mathrm{CuK} \alpha$ radiation (wavelength $1.5405 \AA$ ) and in exploration mode by steps ( $2 \theta$ range: $5^{\circ}$ to $50^{\circ}$ ) in a XRD, Empyrean, Siemens equipment, USA. The diffractograms were deconvolution using Origin Pro 2018 software by adjusting crystalline and amorphous peak sum into each original curve via lorentzian deconvolution. The crystallinity index $\left(I_{c} \%\right)$ of the nanofibers and PALF was determined by the acquired spectrum using Eq. 2 [10, 33].

$I_{c} \%=\left(1-\frac{A a}{A t}\right) * 100$

where: $\mathrm{A} a$ is the area under the curve corresponding to the amorphous portion and $\mathrm{A} t$ is the total area of the diffractograms.

\section{Results and Discussion}

\section{Chemical Composition of the Pineapple Leaves}

During the isolation of cellulose nanofibers, the starting PALF must be exposed to different reactions that generate chemical composition changes. The initial stage uses an alkaline treatment to remove lignin, hemicellulose and ash [34]. Afterward, sodium hypochlorite is used to bleach the sample and remove the remaining lignin, depending on the reaction time, noting that after $5 \mathrm{~h}$ the fibers start to degrade [35]. The chemical composition of the PALF is summarized in Table 1, which indicates that cellulose is the most important component (45\%), followed by lignin (26\%) and hemicelluloses $(17 \%)$. The latter component must be eliminated

Table 1 Chemical composition of the pineapple leaf fiber (PALF)

\begin{tabular}{llllll}
\hline $\begin{array}{l}\text { Cellulose } \\
(\%)\end{array}$ & $\begin{array}{l}\text { Lignin } \\
(\%)\end{array}$ & $\begin{array}{l}\text { Hemicel- } \\
\text { luloses } \\
(\%)\end{array}$ & Ash $(\%)$ & $\begin{array}{l}\text { Acetone } \\
\text { extracta- } \\
\text { bles }(\%)\end{array}$ & $\begin{array}{l}\text { Water } \\
\text { extracta- } \\
\text { bles }(\%)\end{array}$ \\
\hline $45.3 \pm 2.5$ & $25.6 \pm 1.3$ & $17.4 \pm 3.4$ & $4.6 \pm 0.2$ & $3.9 \pm 0.2$ & $3.1 \pm 0.2$ \\
\hline
\end{tabular}


during the alkaline treatment and bleaching. The results are comparable to data from dos Santos et al. 2013, who found $36 \%, 23 \%$ and $28 \%$ of the respective components in Brazilian PALF. However, the biggest difference is regarding the percentage of cellulose and can be attributed to differences in sample preparation, method of extraction, geographical and climatic conditions where the pineapple grows [36]. A remarkable aspect is the presence of the three components and high cellulose content, which makes this material interesting for the production of CNF.

\section{TEMPO Treatment of Pineapple Cellulose}

The cellulose from the bleached and unbleached pineapple leaves was modified through TEMPO oxidation before microfluidization. In general, the difference between the bleached and unbleached CNF was the presence of lignin and hemicelluloses. These compounds can later interact with TEMPO. Indeed, the degree of oxidation for the bleached cellulose samples was higher $(8.8 \%)$ than that of the unbleached sample (6.6\%). This can be attributed to reagent consumption by lignin and possibly a barrier effect generated by the oxidizable groups and the lower cellulose content, which is the substrate for the reaction. An intermediate species formed during oxidation is the aldehyde group, which can reach a concentration of $0.2-0.3 \mathrm{~mol} / \mathrm{g}$. This value corresponds approximately to one aldehyde per 20-30 monomeric repeating units, depending on the concentration and volume of $\mathrm{NaClO}$ added, reaction time and the nature of the sample that is being oxidized [37, 38] (see Table 2).

Also the lower carboxylate contents in the CNF-UB after the oxidation is due to $\mathrm{NaClO}$ reacting with the lignin during the bleaching process rather than forming carboxylates on the surface, which generates a change of color of the sample from dark green to lighter green shade [39].

\section{Cellulose Nanofibers Characterization}

FTIR spectra of pineapple fibers, pineapple cellulose and CNF-B and CNF-UB after oxidation are shown in Fig. 1. In general, all the spectra show the characteristic signals of cellulosic material (OH: $\left.3335 \mathrm{~cm}^{-1}\right),\left(\mathrm{CH}: 2895 \mathrm{~cm}^{-1}\right)$, $\left(\mathrm{C}=\mathrm{O}, \mathrm{CC}\right.$ and $\mathrm{CO}: 1140 \mathrm{~cm}^{-1}$ and $\left.1030 \mathrm{~cm}^{-1}\right)$ and $(\mathrm{COC}$ : $894 \mathrm{~cm}^{-1}$ ). In Fig. 1, a new band appears at $1730 \mathrm{~cm}^{-1}$,

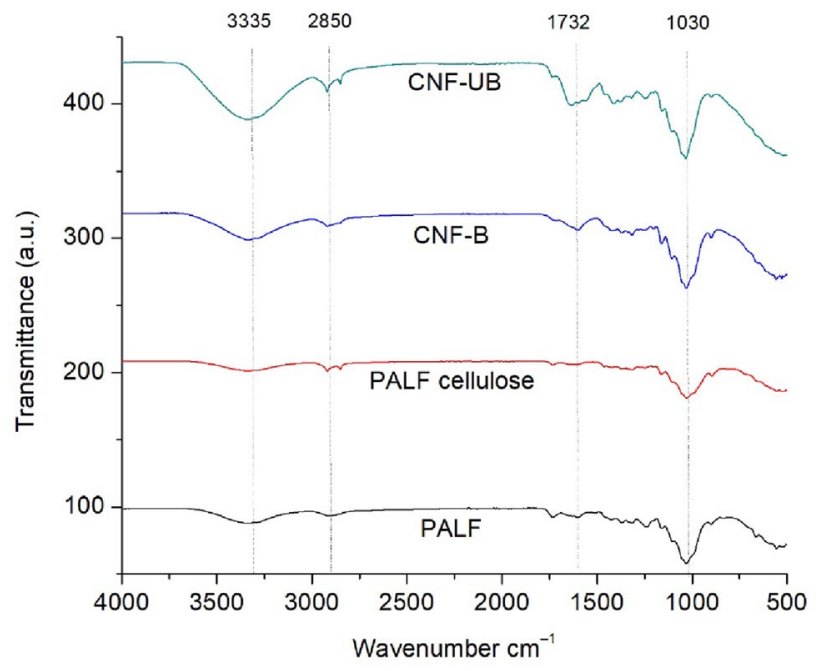

Fig. 1 FTIR of the cellulosic materials: PALF, PALF cellulose, CNF-B and CNF-UB

which corresponds to the $\mathrm{C}=\mathrm{O}$ stretching vibration of carboxyl groups in their acidic form. This suggests that the hydroxymethyl groups of the D-glucose unit were successfully converted into carboxyl groups, even though the signal at $1732 \mathrm{~cm}^{-1}$ was less intense [40]. The percentage of carboxylate groups was demonstrated to increase upon changing the reaction conditions, as reported by Okita, et al. 2010 [41], who used a concentration of $10 \mathrm{mmol} / \mathrm{g}$ of $\mathrm{NaClO}$ and $\mathrm{pH} 10$ during the entire reaction and determined that more than $90 \%$ of the oxidized groups were turned to carboxylates. Taking this into account, $1.2 \mathrm{mmol} / \mathrm{g}$ of $\mathrm{NaClO}$ was added, which is a lower concentration. Therefore, a low aldehyde content was expected. The $\mathrm{pH}$ of the reaction was not kept at 10 during the $3 \mathrm{~h}$; meanwhile, the speed of the reaction diminished as $\mathrm{NaOH}$ was consumed; thus, the content of carboxylates on the cellulose was not optimum and the signal at $1732 \mathrm{~cm}^{-1}$ was not as intense in the spectra of CNF-B and CNF-UB.

The TEMPO reaction tends to occur in the less ordered regions of the system, which are more accessible to the chemical reagents. The degree of dispersion increases, which helps to have a more orderly rearrangement of the cellulose chains, causing a higher percentage of
Table 2 Conductimetric titrations of the TEMPO oxidized samples

\begin{tabular}{lllll}
\hline Sample & $\begin{array}{l}\text { COONa content } \\
(\mathrm{mmol} / \mathrm{g})\end{array}$ & CHO content $(\mathrm{mmol} / \mathrm{g})$ & Total DO $^{\mathrm{a}}(\%)$ & Efficiency $^{\mathrm{b}}$ \\
\hline NFC-B & $0.320 \pm 0.002$ & $0.214 \pm 0.002$ & $8.75 \pm 0.04$ & $70.8 \pm 0.2$ \\
NFC-UB & $0.213 \pm 0.002$ & $0.193 \pm 0.002$ & $6.63 \pm 0.03$ & $51.1 \pm 0.2$ \\
\hline
\end{tabular}

${ }^{a}$ Degree of oxidation per unit of anhydroglucose cellulose, as percentage. ${ }^{b}$ Efficiency defined by $\left(\mathrm{C}_{\mathrm{CHO}}+2 \mathrm{C}_{\mathrm{COOH}}\right) / \mathrm{C}_{\mathrm{NaClO}}$ where $\mathrm{C}_{\mathrm{CHO}}$ y $\mathrm{C}_{\mathrm{COOH}}$ are the quantity of aldehyde and carboxylate groups generated and $\mathrm{C}_{\mathrm{NaClO}}$ is the quantity of $\mathrm{NaClO}$ added 
crystallinity in the CNFs than the original PALF sample (without TEMPO oxidation), as observed in Table 3 [38].

The CNF-B and CNF-UB have a higher degree of crystallinity than the original PALF. Despite the higher crystallinity of the TEMPO-modified samples, it is important to note that the crystallinity values are low (64\%) when compared to other cellulose nanofibers from sources such as soy hulls [42], agave bagasse, 68\% [43] and banana peel, 66\% [44]. The crystallinity index was calculated using the Segal empirical formula from the $\mathrm{X}$ ray deconvolution curve of

Table 3 Crystallinity index of cellulose before and after oxidation

\begin{tabular}{ll}
\hline Sample & $\begin{array}{l}\text { Crystallinity } \\
\text { index (Ic\%) }\end{array}$ \\
\hline PALF & 55.0 \\
CNF-B & 64.0 \\
CNF-UB & 63.5 \\
\hline
\end{tabular}

the diffraction spectra (Fig. 2)[10]. From the XRD spectra, two characteristics peaks of type III cellulose can be observed that correspond with the peaks at $15.1^{\circ}$ and $22.5^{\circ}$ on the planes (100) and (110), respectively [45]. No significant changes in the peak positions were observed, only the increase in the intensity of the peaks was observed in the samples CNF-B and CNF-UB after TEMPO oxidation. This is due to the introduction of aldehyde groups on the surface, that allow better separation and re-accommodation of the fibers. Moreover, a more intense peak can be observed in the CNF-B sample, which also presents a higher degree of oxidation.

The morphology of the fibers obtained after the TEMPO oxidation is confirmed from the AFM images (Fig. 3). These images suggested that the chemical and mechanical treatments removed the cementing materials around the fiberbundles (hemicellulose and lignin) and this resulted in individual fibrils in a well dispersed network.
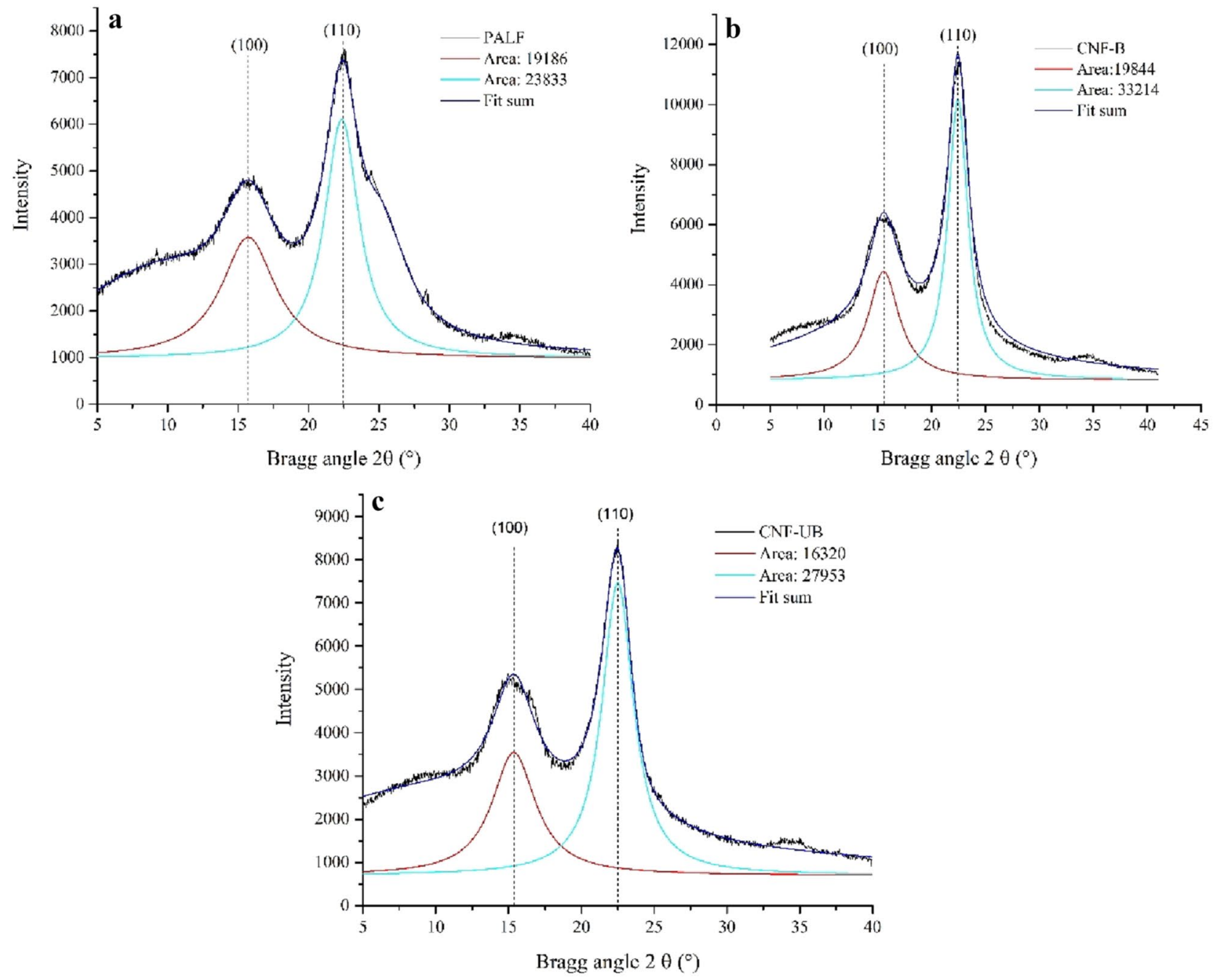

Fig. 2 XRD of the cellulosic materials: a PALF, b CNF-B and c CNF-UB 

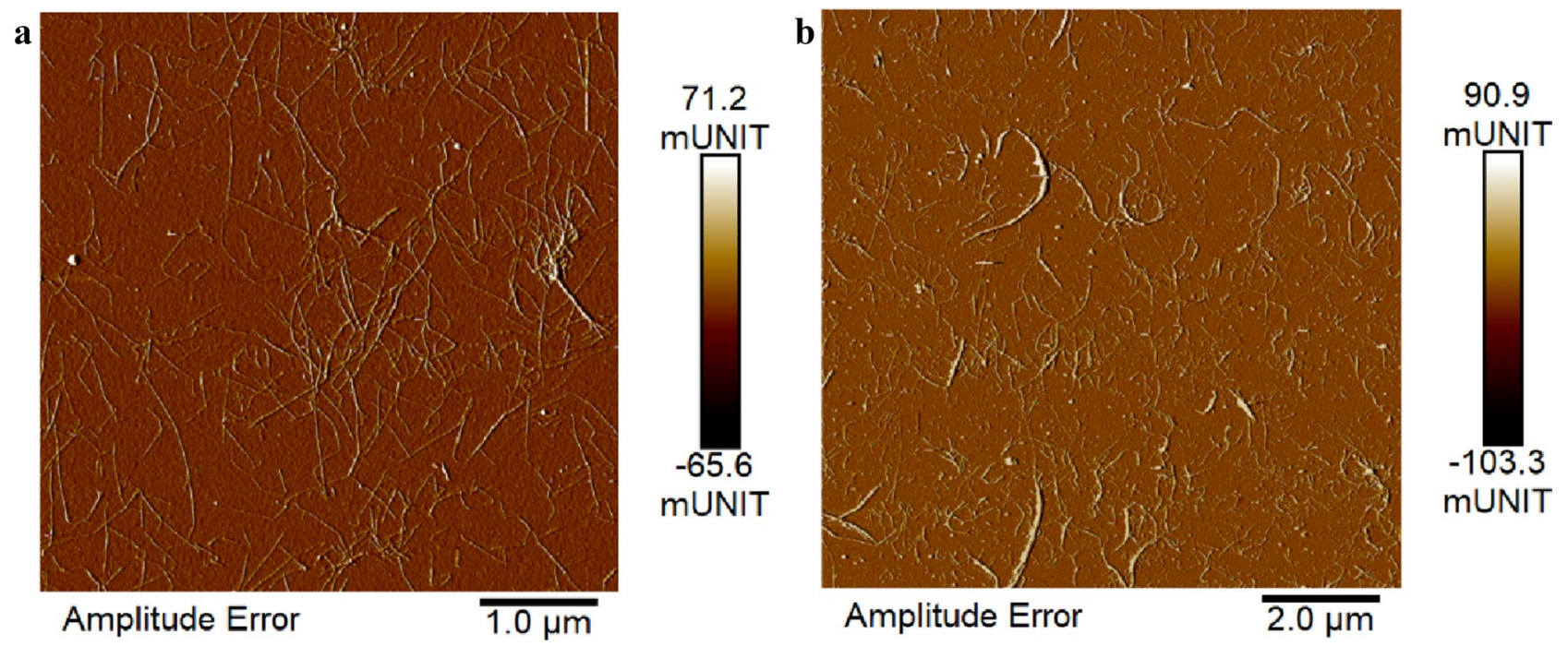

Fig. 3 AFM image of bleached and unbleached cellulose nanofibers: a CNF-B and b CNF-UB

The CNF had diameters between $16 \mathrm{~nm}$ and $48 \mathrm{~nm}$, showing that the treatments were effective in producing nanoscale materials from PALF fibers (Table 4). The CNF-B was thinner, with average diameters of $15.5 \pm 6.14 \mathrm{~nm}$ compared to CNF-UB, $47.9 \pm 10.4 \mathrm{~nm}$. The diameters for CNF-B were similar to the nanofibers isolated from banana peels (12-22 nm) and lower than those of other nanosized structures derived from other sources such as nanofibers from rice straw $(12-35 \mathrm{~nm})$, wheat straw $(15-35 \mathrm{~nm})$ and sugarcane bagasse $(30 \mathrm{~nm})$ [46].

The z-potential differences between CNF-B and CNF-UB see Table 4 , indicate that the former has more electrostatic repulsion between adjacent and similarly charged particles in a dispersion than the latter. This is related to the highest degree of oxidation of the CNF-B since it has a greater number of carboxylate groups and therefore the biggest repulsion betwixt nanofibers [47]. The negative values of z-potential in the samples indicate that almost all free carboxyl groups were dissociated to provide anionic surface charges in water [48]. Table 4 shows that all the nanofiber suspensions exhibited a negative zeta potential. The zeta potential indicates the stability of colloidal suspensions, due to the electrostatic repulsion. The zeta potential of CNF-B was higher than that of CNF-UB.

Figure 4 shows the thermogravimetric curves of the PALF, PALF cellulose, CNF-B and CNF-UB samples. A small mass loss occurred in all the cases in the $\mathrm{T}$ range between $50{ }^{\circ} \mathrm{C}$ and $150{ }^{\circ} \mathrm{C}$ due to water evaporation and loses of low molecular weight compounds trapped in the material (approximately 7\%) [49]. The maximum thermal decomposition point is observed in the DTG curve at $293{ }^{\circ} \mathrm{C}$ for PALF; this value is lower for PALF cellulose $\left(322{ }^{\circ} \mathrm{C}\right)$, due to the hemicellulose, lignin and pectins extraction which are degraded at a lower temperature [50].

In the DTG curves, two signals can be observed at $261^{\circ} \mathrm{C}$ and $321{ }^{\circ} \mathrm{C}$ for the CNF-B sample and at $273{ }^{\circ} \mathrm{C}$ and $317{ }^{\circ} \mathrm{C}$ for the CNF-UB sample (Table 5). These signals are mainly attributed to the initial degradation of the sodium anhydroglucuronate units that are formed during TEMPO oxidation, followed by the decomposition of the rest of the cellulose. The last DTG signal on both spectrums is similar to the thermograph of the cellulose. This is due to the fact that the anhydroglucuronate is more thermally unstable which generates a chain effect causing the cellobiose units to degrade at a lower temperature [28].

\section{Conclusions}

CNF was obtained from pineapple residues using TEMPO oxidation of bleached and unbleached cellulose followed by microfluidization. The results indicated PALF as a suitable
Table $4 \mathrm{Z}$ potential and fiber size of the bleached and unbleached cellulose nanofibers

\begin{tabular}{lllcc}
\hline Sample & Zeta potential $(\mathrm{mV})$ & Fiber size & Aspect ratio L/D \\
\cline { 3 - 4 } & & Length, L $(\mathrm{nm})$ & Diameter, D (nm) & \\
\hline CNF-B & $-41 \pm 5$ & $482 \pm 128$ & $16 \pm 6$ & $31 \pm 2$ \\
CNF-UB & $-31 \pm 8$ & $747 \pm 246$ & $48 \pm 10$ & $16 \pm 1$ \\
\hline
\end{tabular}



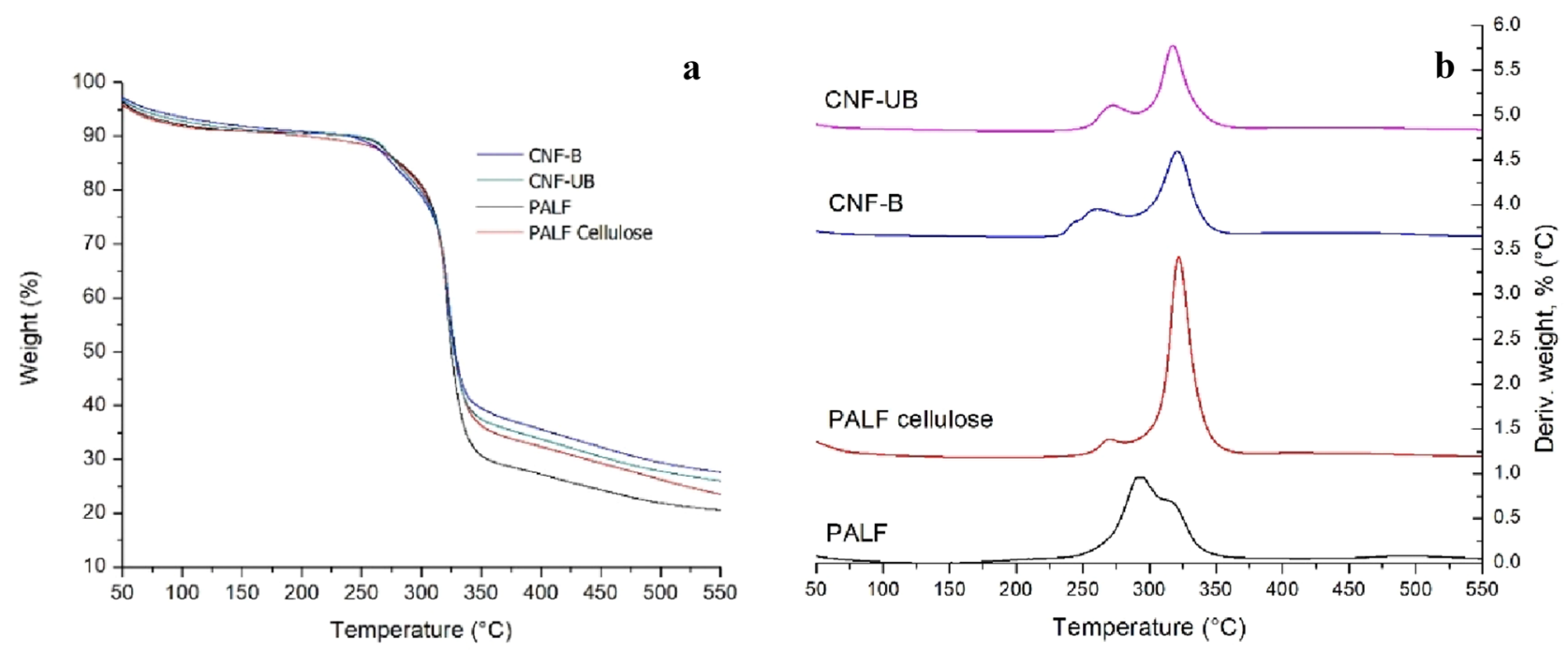

Fig. 4 TGA analysis: a TGA thermograms of PALF, PALF cellulose, bleached and unbleached cellulose nanofibers and b DTGA curves of PALF, PALF cellulose, bleached and unbleached cellulose nanofibers

Table 5 TGA results for PALF, cellulose PALF, bleached and unbleached cellulose nanofibers

\begin{tabular}{llllll}
\hline Sample & $\begin{array}{l}\text { Onset initial degrada- } \\
\text { tion temperature }\left({ }^{\circ} \mathrm{C}\right)\end{array}$ & $\begin{array}{l}\text { Onset final degrada- } \\
\text { tion temperature }\left({ }^{\circ} \mathrm{C}\right)\end{array}$ & $\begin{array}{l}\% \text { Residual } \\
\text { mass at } 600 \\
\left({ }^{\circ} \mathrm{C}\right)\end{array}$ & $\begin{array}{l}\text { DTG T1 } \\
\max \left({ }^{\circ} \mathrm{C}\right)\end{array}$ & $\begin{array}{l}\text { DTG } \\
\text { T2 max } \\
\left({ }^{\circ} \mathrm{C}\right)\end{array}$ \\
\hline PALF & 272 & 330 & 17.88 & - & 293 \\
PALF Cellulose & 259 & 333 & 20.07 & - & 322 \\
CNF-B & 244 & 333 & 26.05 & 261 & 321 \\
CNF-UB & 260 & 330 & 24.53 & 273 & 317 \\
\hline
\end{tabular}

source for CNF under a reduced number of steps. The isolated nanofibers presented lengths of $482 \mathrm{~nm}$ and $747 \mathrm{~nm}$, with an aspect ratio of 16 and 31 , zeta potentials of $-41 \mathrm{mV}$ for CNF-B and $-31 \mathrm{mV}$ for CNF-UB. They also showed higher crystallinity compared to the fibrous starting material. There is evidence that the thermal stability of the material is affected by the chemical treatment, since the degradation temperature was reduced. A key finding is that the characteristics found in pineapple cellulose nanofibers show that this nanomaterial can have diverse applications, such as composites or thin layers coated in laminated films for generic and cutting-edge products and wet- end additive or coating to improve the properties of cardboard in the paper and packaging industry.

The bleached and unbleached CNFs presented similar characteristics, which implies that in the production process it is possible to reduce the amount of bleaching chemicals and only use TEMPO oxidation process, since only $0.1 \mathrm{mmol}$ of TEMPO will be used per $\mathrm{g}$. of cellulose. Chemical modification with TEMPO makes cellulose fibers easier for microfibrillating, reducing the steps carried out by the equipment and reducing the energy consumed by the mechanical microfluidization process. These changes in operation could reduce expenses and make the process more cost-effective. The two main benefits found in this research are the production of a biomaterial with potential applications and a solution to the serious environmental damage caused by agro-industrial waste.

Funding The Universidad Nacional, through the project number 056917 , as well as the fund to support student capabilities in investigation (FOCAES) funded this research.

Code Availability Not applicable.

\section{Declarations}

Conflict of Interest The authors declare that they have no conflict of interest.

Open Access This article is licensed under a Creative Commons Attribution 4.0 International License, which permits use, sharing, adaptation, distribution and reproduction in any medium or format, as long as you give appropriate credit to the original author(s) and the source, provide a link to the Creative Commons licence, and indicate if changes 
were made. The images or other third party material in this article are included in the article's Creative Commons licence, unless indicated otherwise in a credit line to the material. If material is not included in the article's Creative Commons licence and your intended use is not permitted by statutory regulation or exceeds the permitted use, you will need to obtain permission directly from the copyright holder. To view a copy of this licence, visit http://creativecommons.org/licenses/by/4.0/.

\section{References}

1. Canapep. Estadísticas de la Camara Nacional de Productores y Exportadores de Piña. Available online: https://canapep.com/ estadisticas/. Accessed 9 March 2020.

2. PROCOMER. Exportaciones de Portal Estadistico de Comercio Exterior. Available online: http://sistemas.procomer.go.cr/estad isticas/inicio.aspx. Accessed 15 Jan 2019.

3. Rigg-Aguilar, P., Moya, R., Oporto-Velásquez, G.S., VegaBaudrit, J., Starbird, R., Puente-Urbina, A., Méndez, D., Potosme, L.D., Esquivel, M.: Micro- and Nanofibrillated Cellulose (MNFC) from Pineapple (Ananas comosus) Stems and Their Application on Polyvinyl Acetate (PVAc) and Urea-Formaldehyde (UF) Wood Adhesives. J. Nanomater. 2020, 1-12 (2020). https://doi.org/10.1155/2020/1393160

4. Nennie, I., De Boer, H.: Sustainable Pineapple Costa RicaMarket Study. Available online: https://www.rvo.nl/sites/default/ files/2018/06/sustainable-pineapple-costa-rica-market-study. pdf. Accessed 10 Oct 2020.

5. Echeverría-Sáenz, S., Mena, F., Pinnock, M., Ruepert, C., Solano, K., De la Cruz, E., Campos, B., Sánchez-Avila, J., Lacorte, S., Barata, C.: Environmental hazards of pesticides from pineapple crop production in the Río Jiménez watershed (Caribbean Coast, Costa Rica). Science of the Total Environmet 440, 106-114 (2012). https://doi.org/10.1016/j.scitotenv.2012. 07.092

6. Lopattananon, N., Panawarangkul, K., Sahakaro, K., Ellis, B.: Performance of pineapple leaf fiber-natural rubber composites: the effect of fiber surface treatments. J. Appl. Polym. Sci. 102, 974-1984 (2006). https://doi.org/10.1002/app.24584

7. Martone, P.T., Estevez, J.M., Lu, F., Ruel, K., Denny, M.W., Somerville, C., Ralph, J.: Discovery of lignin in seaweed reveals convergent evolution of cell-wall architecture. Curr. Biol. 19, 169-175 (2009). https://doi.org/10.1016/j.cub.2008.12.031

8. O'Sullivan, A.: Cellulose: the structure slowly unravels. Cellulose 4, 173-207 (1997). https://doi.org/10.1023/A:1018431705579

9. Puls, J.: Chemistry and biochemistry of hemicelluloses: Relationship between hemicellulose structure and enzymes required for hydrolysis. Macromolecular Symposia (1997). https://doi. org/10.1002/masy.19971200119

10. Sena Neto, A.R., Araujo, M.A.M., Barboza, R.M.P., Fonseca, A.S., Tonoli, G.H.D., Souza, F.V.D., Mattoso, L.H.C., Marconcini, J.M.: Comparative study of 12 pineapple leaf fiber varieties for use as mechanical reinforcement in polymer composites. Industrial Crops and Products 64, 68-78 (2015). https://doi.org/ 10.1016/j.indcrop.2014.10.042

11. Cherian, B.M., Leão, A.L., De Souza, S.F., Thomas, S., Pothan, L.A., Kottaisamy, M.: Isolation of nanocellulose from pineapple leaf fibres by steam explosion. Carbohyd. Polym. 81, 720-725 (2010). https://doi.org/10.1016/j.carbpol.2010.03.046

12. Salas, C., Nypelö, T., Rodriguez-Abreu, C., Carrillo, C., Rojas, O.J.: Nanocellulose properties and applications in colloids and interfaces. Curr. Opin. Colloid Interface Sci. 19, 383-396 (2014). https://doi.org/10.1016/j.cocis.2014.10.003

13. Scatolino, M.V., Fonseca, C.S., da Silva Gomes, M., Rompa, V.D., Martins, M.A., Tonoli, G.H.D., Mendes, L.M.: How the surface wettability and modulus of elasticity of the Amazonian paricá nanofibrils films are affected by the chemical changes of the natural fibers. Eur J Wood Wood Prod 76, 1581-1594 (2018). https://doi.org/10.1007/s00107-018-1343-7

14. Scatolino, M.V., Bufalino, L., Mendes, L.M., Guimarães Júnior, M., Tonoli, G.H.D.: Impact of nanofibrillation degree of eucalyptus and Amazonian hardwood sawdust on physical properties of cellulose nanofibril films. Wood Science and Technology 51, 1095-1115 (2017). https://doi.org/10.1007/s00226-017-0927-4

15. Kargupta, W., Seifert, R., Martinez, M., Olson, J., Tanner, J., Batchelor, W.: Sustainable production process of mechanically prepared nanocellulose from hardwood and softwood: a comparative investigation of refining energy consumption at laboratory and pilot scale. Industrial Crops and Products (2021). https://doi.org/ 10.1016/j.indcrop.2021.113868

16. Fonseca, C.S., Scatolino, M.V., Silva, L.E., Martins, M.A., Guimarães Júnior, M., Tonoli, G.H.D.: Valorization of jute biomass: performance of fiber-cement composites extruded with hybrid reinforcement (Fibers and Nanofibrils). Waste Biomass Valorization 12, 5743-5761 (2021). https://doi.org/10.1007/ s12649-021-01394-1

17. Santos, E.M., Escalante, M.A., Gutiérrez Becerra, A., SulbaránRangel, B.: Unbleached cellulose from waste corncob for isolation of cellulose nanocrystals. Emerg Mater Res 9, 1258-1265 (2020). https://doi.org/10.1680/jemmr.20.00073

18. Sulbarán-Rangel, B., Hernández Díaz, J.A., Guzmán González, C.A., Rojas, O.J.: Partially acetylated cellulose nanofibrils from Agave tequilana bagasse and Pickering stabilization. J Dispersion Sci Technol (2020). https://doi.org/10.1080/01932691.2020. 1858855

19. Miller, J.: Nanocellulose producers, products, and applications: a guide for end users. Tappi Press, Madison (2017).

20. Kumari, S., Chauhan, R.P.S., Mishra, A., Kumar, P.: A review on nanocellulose and its potential biomedical applications. Trends in Biomaterials and Artificial Organs 35, 303-315 (2021). https:// doi.org/10.1201/9780429327766-8

21. De France, K., Zeng, Z., Wu, T., Nyström, G.: Functional materials from nanocellulose: utilizing structure-property relationships in bottom-up fabrication. Advanced Materials (2021). https://doi. org/10.1002/adma.202000657

22. Pereira, P.H.F., Ornaghi Júnior, H.L., Coutinho, L.V., Duchemin, B., Cioffi, M.O.H.: Obtaining cellulose nanocrystals from pineapple crown fibers by free-chlorite hydrolysis with sulfuric acid: physical, chemical and structural characterization. Cellulose 27, 5745-5756 (2020). https://doi.org/10.1007/s10570-020-03179-6

23. Faria, L.U.S., Pacheco, B.J.S., Oliveira, G.C., Silva, J.L.: Production of cellulose nanocrystals from pineapple crown fibers through alkaline pretreatment and acid hydrolysis under different conditions. J. Market. Res. 9, 12346-12353 (2020). https://doi.org/10. 1016/j.jmrt.2020.08.093

24. Agarwal, J., Mohanty, S., Nayak, S.K.: Valorization of pineapple peel waste and sisal fiber: study of cellulose nanocrystals on polypropylene nanocomposites. J Appl Polym Sci (2020). https:// doi.org/10.1002/app.49291

25. Moreno, G., Ramirez, K., Esquivel, M., Jimenez, G.: Isolation and characterization of nanocellulose obtained from industrial crop waste resources by using mild acid hydrolysis. J Renew Mater $\mathbf{6}$, 1-8 (2017). https://doi.org/10.7569/JRM.2017.634167

26. Sainorudin, M.H., Abdullah, N.A., Asmal Rani, M.S., Mohammad, M., Mahizan, M., Shadan, N., Abd Kadir, N.H., Yaakob, Z., El-Denglawey, A., Alam, M.: Structural characterization of microcrystalline and nanocrystalline cellulose from Ananas comosus L. leaves: cytocompatibility and molecular docking studies. Nanotechnol Rev 10, 793-806 (2021). https://doi.org/10.1515/ ntrev-2021-0053 
27. Palacios, H., Urena-Saborio, H., Zurita, F., Guerrero de León, A.A., Sundaram, G., Sulbarán-Rangel, B.: Nanocellulose and polycaprolactone nanospun composite membranes and their potential for the removal of pollutants from water. Molecules 25, 683 (2020). https://doi.org/10.3390/molecules 25030683

28. Isogai, A., Saito, T., Fukuzumi, H.: TEMPO-oxidized cellulose nanofibers. Nanoscale (2011). https://doi.org/10.1039/c0nr00583e

29. ASTM D1721-97.: Standard test method for permanganate time of tricresyl phosphate (Withdrawn 2012). ASTM International, West Conshohocken, PA, www.astm.org (2007).

30. ASTM D1106-21.: Standard Test Method for Acid-Insoluble Lignin in Wood. ASTM International, West Conshohocken, PA, www.astm.org (2021).

31. ASTM D1104-78.: Method of Test for Holocellulose in Wood. ASTM International, West Conshohocken, PA, www.astm.org. (1978).

32. ASTM D3174-12.: Standard Test Method for Ash in the Analysis Sample of Coal and Coke from Coal. ASTM International, West Conshohocken, PA, www.astm.org (2018).

33. Segal, L., Creely, J.J., Martin, A.E., Conrad, C.M.: An empirical method for estimating the degree of crystallinity of native cellulose using the X-ray diffractometer. Text. Res. J. 29, 786-794 (1959)

34. Deepa, B., Eldho, A., Cordeiro, N., Mozetic, M., Mathew, A.P., Oksman, K., Faria, M., Thomas, S., Pothan, L.A.: Utilization of various lignocellulosic biomass for the production of nanocellulose: a comparative study. Cellulose 22, 1075-1090 (2015). https://doi.org/10.1007/s10570-015-0554-x

35. Fareez, I.M., Ibrahim, N.A., Wan Yaacob, W., Mamat, N.A., Jasni, A.H., Aziz, F.A.: Characteristics of cellulose extracted from Josapine pineapple leaf fibre after alkali treatment followed by extensive bleaching. Cellulose 25, 4407-4421 (2018). https:// doi.org/10.1007/s10570-018-1878-0

36. Chandrasekhar, S., Satyanarayana, K.G., Pramada, P.N.: Processing, properties and applications of reactive silica from rice huskan overview. J. Mater. Sci. 38, 3159-3168 (2003). https://doi.org/ 10.1023/A:1025157114800

37. Saito, T., Nishiyama, Y., Putaux, J.L., Vignon, M., Isogai, A.: Homogeneous suspensions of individualized microfibrils from TEMPO-catalyzed oxidation of native cellulose. Biomacromolecules (2006). https://doi.org/10.1021/bm060154s

38. Huiyang, B., Liheng, C., Hongqi, D., Zhu, J.Y.: Integrated production of lignin containing cellulose nanocrystals (LCNC) and nanofibrils (LCNF) using an easily recyclable di-carboxylic acid. Carbohyd. Polym. 167, 167-176 (2017). https://doi.org/10.1016/j. carbpol.2017.03.050

39. Herrera, M., Thitiwutthisakul, K., Yang, X., Rujitanaroj, P., Rojas, R., Berglund, L.: Preparation and evaluation of high-lignin content cellulose nanofibrils from eucalyptus pulp. Cellulose 25, 31213133 (2018). https://doi.org/10.1007/s10570-018-1764-9

40. Tang, Z., Li, W., Lin, X., Xiao, H., Miao, Q., Huang, L., Chen, L., Wu, H.: TEMPO-Oxidized cellulose with high degree of oxidation. Polymers (2017). https://doi.org/10.3390/polym90904 21

41. Okita, Y., Saito, T., Isogai, A.: Entire surface oxidation of various cellulose microfibrils by TEMPO-mediated oxidation. Biomacromol 11, 1696-1700 (2010). https://doi.org/10.1021/bm100214b

42. Alemdar, A., Sain, M.: Isolation and characterization of nanofibers from agricultural residues-Wheat straw and soy hulls. Biores. Technol. 99, 664-1671 (2008). https://doi.org/10.1016/j.biortech. 2007.04.029

43. Palacios, H., Hernandez, J.A., Esquivel, M., Toriz, G., Rojas, O., Sulbaran, B.C.: Isolation and characterization of nanofibrillar cellulose from Agave tequilana Weber Bagasse. Adv Mater Sci Eng (2019). https://doi.org/10.1155/2019/1342547

44. Tibolla, H., Pelissari, F.M., Martins, J.T., Lanzoni, E.M., Vicente, A.A., Menegalli, F.C., Cunha, R.L.: Banana starch nanocomposite with cellulose nanofibers isolated from banana peel by enzymatic treatment: In vitro cytotoxicity assessment. Carbohyd. Polym. 207, 169-179 (2019). https://doi.org/10.1016/j.carbpol.2018.11. 079

45. French, A.D.: Idealized powder diffraction patterns for cellulose polymorphs. Cellulose 21, 885-896 (2014). https://doi.org/10. 1007/s 10570-013-0030-4

46. Pelissari, F.M., Sobral, P.J.A., Menegalli, F.C.: Isolation and characterization of cellulose nanofibers from banana peels. Cellulose 21, 417-432 (2014). https://doi.org/10.1007/s10570-013-0138-6

47. Cintil, J.C., A. Jiji, K.M. Raghvendra, G. Soney, and T. Sabu, Chapter 1 - Instrumental Techniques for the Characterization of Nanoparticles, in Thermal and Rheological Measurement Techniques for Nanomaterials Characterization. R.Thomas S.Thomas, A. K. Zachariah, R. K. Mishra, Editor. 2017, Elsevier, 1-36.

48. Fujisawa, S., Okita, Y., Fukuzumi, H., Saito, T., Isogai, A.: Preparation and characterization of TEMPO-oxidized cellulose nanofibril films with free carboxyl groups. Carbohyd. Polym. 84, 579-583 (2011). https://doi.org/10.1016/j.carbpol.2010.12.029

49. Do Santos, R.M., Flauzino, W.P., Silvério, H.A., Martins, D.F., Dantas, N.O., Pasquini, D.: Cellulose nanocrystals from pineapple leaf, a new approach for the reuse of this agro-waste. Indust Crop Prod 50, 707-714 (2013). https://doi.org/10.1016/j.indcrop.2013. 08.049

50. Wenshuai, C., Haipeng, Y., Yixing, L., Yunfei, H., Mingxin, Z., Peng, C.: Isolation and characterization of cellulose nanofibers from four plant cellulose fibers using a chemical-ultrasonic process. Cellulose 18, 433-442 (2011). https://doi.org/10.1007/ s10570-011-9497-z

Publisher's Note Springer Nature remains neutral with regard to jurisdictional claims in published maps and institutional affiliations. 